\title{
ACUTE PANCREATITIS AND ITS COMPLICATIONS: MDCT VERSUS USG: AN OVERVIEW
}

\author{
Aejaz Ahmed Gonegandla', Ayesha², G. Naga Karthik ${ }^{3}$, Jaya Nethagani ${ }^{4}$
}

${ }^{1}$ Senior Resident, Department of Radiology, MNJIO \& RCC.

${ }^{2}$ Assistant Professor, Department of Radiology, MNJIO \& RCC.

${ }^{3}$ Senior Resident, Department of Radiology, MNJIO \& RCC.

${ }^{4}$ Professor, Department of Radiology, MNJIO \& RCC.

\section{ABSTRACT}

\section{OBJECTIVE}

Imaging plays a central role in the management of selected cases of acute pancreatitis and its complications, complementing laboratory investigations such as serum amylase and lipase levels that have relatively high sensitivity and specificity. In addition to clinical signs and laboratory investigations, imaging helps in confirming the clinical diagnosis when there is uncertainty and elucidates the cause and grade the extent and severity of acute pancreatitis. It also aids in the early detection of complications.

\section{MATERIAL AND METHODS}

Ultrasound and CECT Abdomen were done in 55 patients with a typical clinical suspicion of acute pancreatitis. The findings were correlated with biochemical parameters and the discrepancy between the two modalities i.e. USG and CT was evaluated.

\section{RESULTS}

About 55 cases were studied and they were subjected to USG and CT (plain and contrast). Most of the patients were males with male to female ratio 13:1. Most common aetiology was chronic alcohol consumption (42 cases, 76.33\%) followed by idiopathic (11 cases, $20 \%$ ) and trauma ( 2 cases, 3.66\%). Multiple sites of involvement ( 35 cases, $63.65 \%$ ) was more common than focal involvement of pancreas. Severe form of pancreatitis (37 cases, 67.27\%) was the most common type according to MCTSI. The most common complication was ascites (cases, 56.36\%) and pleural effusion (16 cases, 29.09\%).

\section{CONCLUSION}

The sensitivity of USG in detecting acute pancreatitis was $41.8 \%$. The sensitivity of CT (plain and contrast) in detecting pancreatitis was $100 \%$. Modified CT severity index shows significant correlation between severity of pancreatitis and patient outcome. Serum lipase is more accurate in detecting acute pancreatitis than serum amylase. Thus, from the present study, it can be concluded that CT (plain and contrast) is superior in detecting and evaluating pancreatitis. Hence, CT plain and contrast should be performed in all cases of clinically suspected pancreatitis especially with positive serological findings.

\section{KEYWORDS}

Acute Pancreatitis, Role of USG and CT, Compare Findings of USG and CT, Predict Outcome of PTS with AC Pancreatitis.

HOW TO CITE THIS ARTICLE: Gonegandla AA, Ayesha, Karthik GN et al. Acute pancreatitis and its complications: MDCT versus USG: An overview. J. Evolution Med. Dent. Sci. 2016;5(72):5302-5306, DOI: 10.14260/jemds/2016/1201

\section{INTRODUCTION}

Pancreatitis is classified into Acute, Chronic, Autoimmune, Groove pancreatitis, Tropical and Hereditary types. Acute pancreatitis is defined as an acute inflammatory state of the pancreas and is conventionally categorised as either mild or severe disease. Approximately, $80 \%$ to $85 \%$ of patients with acute pancreatitis will have the mild form with an uncomplicated clinical course whereas $15 \%$ to $20 \%$ develop a complicated clinical course characterised by organ failure and/or local complications. ${ }^{1}$ It is also an important cause of acute abdominal pain.

Although USG can be used in the evaluation of acute pancreatitis, there is high frequency of indeterminate results in critically ill patients stemming from the inability to image

Financial or Other, Competing Interest: None.

Submission 12-08-2016, Peer Review 27-08-2016,

Acceptance 30-08-2016, Published 08-09-2016.

Corresponding Author:

Dr. Ayesha,

H. No. 8-3-214/50B

Srinivasa Colony,

West Hyderabad-500038.

E-mail: ayesharadio@gmail.com

DOI: $10.14260 /$ jemds/2016/1201 the entire gland and peripancreatic spaces. Despite these potential limitations, there are specific indications for selecting USG in the evaluation of patients with known or suspected acute pancreatitis. Owen J. O'Connor et al reported that ultrasound is potentially a valuable tool in the management and followup of various complications of pancreatitis, facilitating rapid bedside imaging, diagnostic aspiration, and drain insertion. ${ }^{2}$

CT now has revolutionised pancreatic imaging, and what was once considered as a "radiological blind spot" may now be accurately and noninvasively imaged. CT offers high spatial resolution imaging with the ability to accurately detect pancreatitis and its complications, involvement of vascular structures around the pancreas, pancreatic pseudocyst formation and gallbladder calculi. CT can evaluate other acute abdominal catastrophes other than acute pancreatitis.

The CT severity index, developed by Balthazar and colleagues in 1994, was a significant advance because it helps clinicians to discriminate among mild, moderate, and severe forms of pancreatitis. The modified CT severity index included a simplified assessment of pancreatic inflammation and necrosis as well as an assessment of extrapancreatic complications. It showed a stronger correlation for all parameters than the score obtained with the earlier CT index, and also could be used to accurately predict the length of the hospital stay. 


\section{MATERIAL AND METHODS}

- To evaluate the role of USG and CT in acute pancreatitis.

- To compare the findings of USG with CT.

- To correlate USG and CT findings with biochemical parameters.

- To evaluate the occurrence of complications and role of USG and CT.

- To compare the data with previous studies.

- To predict the outcome of patients with acute pancreatitis.

\section{USG Method Followed}

Ultrasound examination is performed using 3-5 $\mathrm{MHz}$ probe after at least 6 hours of fasting to improve visualisation of the pancreas. It is performed along multiple scan planes, including transverse, longitudinal, and angled oblique, to visualise the entire organ: The head with the uncinate process, the body, and the tail.

\section{CT Method Followed}

High quality images can be obtained by increasing the conspicuity of pancreas by vascular opacification, oral contrast agents and by eliminating respiratory motion artefacts and misregistration. A limited non-contrast scan through the pancreas is obtained followed by a rapid IV bolus injection of $50-60 \mathrm{~mL}$ of IV contrast material at a rate of $3.5 \mathrm{~mL} / \mathrm{sec}$. A helical scan is obtained from the top of diaphragm to the iliac crest using $5 \mathrm{~mm}$ collimation and a pitch of 2 , starting $20-25$ seconds after beginning the IV contrast.

A two-phase imaging technique used for acquiring the arterial and venous portal phases. The acquisition for arterial phase images starts 25 seconds after IV contrast over the pancreatic area (Upper border of T12 to upper border of L4 vertebra) using $2.5 \mathrm{~mm}$ collimation. Portal phase starts after a delay of 40-45 seconds after completion of arterial phase, acquiring axial images of $5 \mathrm{~mm}$ collimation (From pubic symphysis to the dome of diaphragm).

\section{SUBJECTS AND RESULTS}

The present study included 55 patients with clinical suspicion of acute pancreatitis who had undergone both USG and MDCT (Plain and contrast).

A total of 31 patients were managed conservatively and 21 patients underwent invasive procedures.

The age group of the patients was wide, ranging from 1180 years. Most common age group was $31-40$ years, ( 21 cases) accounting for $38.18 \%$ with mean age of 35.5 years.

The most common aetiology for acute pancreatitis was chronic alcohol consumption (42 cases) accounting for $76.33 \%$ followed by idiopathic 20\% (11 cases) and trauma $3.63 \%$ ( 2 cases).

The male to female ratio was $13: 1$ with a male preponderance.

USG detected pancreatitis in 23 cases $(41.8 \%)$ and CT detected acute pancreatitis in all cases (100\%).

The most common complication was ascites (36 cases) (65.4\%), followed by pseudocyst (31 cases) (56.3\%), and pleural effusion (16 cases) (29\%).

Eleven cases $(20 \%)$ showed oedematous thickening of the gastric wall and duodenal walls.

Three cases of splenic vein thrombosis were detected.

One case of pseudoaneurysm of splenic artery was detected.

One portal vein thrombosis was detected.
Therefore, in the present study, overall 5 cases developed vascular complications (9.09\%).

One case of avascular necrosis of bilateral heads of femur was also seen.

CT with contrast detected all the cases of acute pancreatitis and found to have positive correlation with clinical and serological parameters.

Serum amylase and lipase levels were used as serological parameters to correlate with CT findings and serum lipase levels were found to be raised in 49 cases (89.09\%), whereas serum amylase levels were elevated only in 36 cases $(65.4 \%)$.

46 out of 55 cases had followup USG during their stay in the hospital, of which 44 cases $(95.65 \%)$ did not show any change from their previous appearances and two cases (4.34\%) showed spontaneous resolution of pseudocyst.

9 out of 55 cases could not have follow p scans as they had left hospital against medical advice.

Out of 55 patients, 48 patients had survived and 7 patients had died.

Most no. of patients were between age group 31-40 years with mean age of 35.5 years.

DISTRIBUTION OF STUDY SUBJECTS ACCORDING TO AETIOLOGY

\begin{tabular}{|c|c|c|}
\hline Sl. No. & Aetiology & No. of Cases (n)/ (\%) \\
\hline 1 & Alcohol & $42(76.33 \%)$ \\
\hline 2 & Idiopathic & $11(20 \%)$ \\
\hline 3 & Trauma & $2(3.66 \%)$ \\
\hline & Total & $\mathbf{5 5 ( 1 0 0 \% )}$ \\
\hline
\end{tabular}

\section{TYPES OF COMPLICATIONS}

\begin{tabular}{|c|c|c|c|c|}
\hline $\begin{array}{c}\text { Sl. } \\
\text { No. }\end{array}$ & Complications & $\begin{array}{c}\text { Total No. } \\
\text { of Cases } \\
(\mathbf{N}) /(\mathbf{6})\end{array}$ & $\begin{array}{c}\text { Detected } \\
\text { by USG } \\
\text { (N) / (\%) }\end{array}$ & $\begin{array}{c}\text { Detected } \\
\text { by CT } \\
(\mathbf{N}) / \mathbf{( \% )}\end{array}$ \\
\hline 1 & Pseudocyst & $\begin{array}{c}31 \\
(56.3 \%)\end{array}$ & $\begin{array}{c}23 \\
(75 \%)\end{array}$ & $\begin{array}{c}31 \\
(100 \%)\end{array}$ \\
\hline 2 & Pleural Effusion & $\begin{array}{c}16 \\
(29.09 \%)\end{array}$ & $\begin{array}{c}16 \\
(100 \%)\end{array}$ & $\begin{array}{c}16 \\
(100 \%)\end{array}$ \\
\hline 3 & Ascites & $\begin{array}{c}36 \\
(65.4 \%)\end{array}$ & $\begin{array}{c}23 \\
(66.66 \%)\end{array}$ & $\begin{array}{c}36 \\
(100 \%)\end{array}$ \\
\hline 4 & $\begin{array}{c}\text { Vascular } \\
\text { Complications }\end{array}$ & $\begin{array}{c}5 \\
(9.09 \%)\end{array}$ & $\begin{array}{c}2 \\
(40 \%)\end{array}$ & $\begin{array}{c}5 \\
(100 \%)\end{array}$ \\
\hline 5 & $\begin{array}{c}\text { Gastrointestinal } \\
\text { Involvement }\end{array}$ & $\begin{array}{c}11 \\
(20 \%)\end{array}$ & $\begin{array}{c}4 \\
(36.36 \%)\end{array}$ & $\begin{array}{c}11 \\
(100 \%)\end{array}$ \\
\hline 6 & $\begin{array}{c}\text { Avascular } \\
\text { Necrosis }\end{array}$ & $\begin{array}{c}1 \\
(1.8 \%)\end{array}$ & 0 & 1 \\
$(0 \%)$ & $(100 \%)$ \\
\hline
\end{tabular}

DISTRIBUTION OF STUDY SUBJECTS ACCORDING TO MODIFIED CT SEVERITY INDEX

\begin{tabular}{|c|c|c|}
\hline Grades & MCTSI & No. of Cases (n)/ (\%) \\
\hline Mild & $0-2$ & $5(9.09 \%)$ \\
\hline Moderate & $4-6$ & $13(23.63 \%)$ \\
\hline Severe & $8-10$ & $37(67.27 \%)$ \\
\hline Total & & $\mathbf{5 5 ( 1 0 0 \% )}$ \\
\hline
\end{tabular}

\section{DETECTION OF CASES BY USG \& MDCT}

\begin{tabular}{|c|c|c|c|}
\hline $\begin{array}{c}\text { Sl. } \\
\text { No. }\end{array}$ & $\begin{array}{c}\text { Detection of Cases } \\
\text { by USG and CT }\end{array}$ & $\begin{array}{c}\text { USG } \\
\text { (N) / (\%) }\end{array}$ & $\begin{array}{c}\text { CT } \\
\text { (N) / (\%) }\end{array}$ \\
\hline 1 & No. of Cases & 23 & 55 \\
$(41.8 \%)$ & $(100 \%)$ \\
\hline
\end{tabular}




\section{DISCUSSION}

Acute pancreatitis is defined as an acute, mainly diffuse, inflammatory process of the pancreas that exhibits great variation in the degree of involvement of the gland, the adjacent retroperitoneal tissues and other remote organ systems. Imaging plays a central role in the management of selected cases of pancreatitis, complementing laboratory investigations such as serum amylase and lipase levels that have relatively high sensitivity and specificity.

The incidence of recurrence after a single episode of acute pancreatitis is quite high. CT is the dominant imaging modality for initially identifying complications and for assessing response to therapy and hence the preference of CT over USG. ${ }^{2}$ The CT findings in acute pancreatitis reflect the presence and extent of the retroperitoneal inflammatory process. The findings are similar irrespective of aetiology with the exception of traumatic pancreatitis in which pancreatic lacerations associated with high density haematomas can sometimes be detected.3,4 Balthazar et al. had divided the spectrum of acute pancreatitis into five grades: Grade A normal pancreas; grade $\mathrm{B}$ pancreatic enlargement; grade $\mathrm{C}$ gland enlargement and peripancreatic tissue inflammatory changes; grade D enlarged gland, peripancreatic inflammatory changes and single peripancreatic fluid collection; and grade $\mathrm{E}$ two or multiple fluid collections or presence of gas in adjacent to the pancreas 5 (abscess formation) (Emil J. Balthazar, 2002).

\section{Acute Pancreatitis Aetiology6}

\begin{tabular}{|ll|}
\hline Metabolic & Alcohol, Hyperlipo-proteinemia Hyper-calcemia, \\
& Drugs, Scorpion venom, Autoimmune Pancreatitis \\
\hline Mechanical & Cholelithiasis, Postoperative condition (Gastric, \\
& Biliary), Post traumatic, Retrograde Pancreato-graphy, \\
& Pancreatic duct obstruction, Pancreatic tumour, Ascaris \\
& infestation, Duodenal obstruction \\
Vascular & Post-operative condition (Cardio-pulmonary bypass), \\
& Polyarteritisnodosa, Athero-embolism \\
Infections & Mumps, Coxsackie virus \\
Drugs & Corticosteroids, azathioprine, 6-mercaptopurine, \\
& thiazide diuretics, furosemide, aminosalicylic acid, \\
Idiopathic & sulfonamides, tetracycline, procainamide, and opiates \\
& Biliary sludge, microlithiasis, congenital \\
\hline
\end{tabular}

The study included 55 patients with history of clinical suspicion of acute pancreatitis who had undergone both USG and MDCT.

\section{PROGNOSTIC CRITERIA USED FOR EVALUATION} Modified CT Severity Index (MCTSI). ${ }^{7}$

\begin{tabular}{|c|c|}
\hline Prognostic Indicator & SCORE \\
\hline Pancreatic Inflammation & 0 \\
\hline Normal Pancreas & 2 \\
\hline $\begin{array}{c}\text { Intrinsic pancreatic abnormalities with/without } \\
\text { inflammatory changes in peripancreatic fat }\end{array}$ & 4 \\
\hline $\begin{array}{c}\text { Pancreatic or peripancreatic fluid collection or } \\
\text { peripancreatic fat necrosis }\end{array}$ & 0 \\
\hline Pancreatic Necrosis & 2 \\
\hline None & 4 \\
\hline <=30\% & 2 \\
\hline $\begin{array}{c}\text { Extrapancreatic Complications } \\
\text { (One or more of pleural effusion, ascites, } \\
\text { vascular complications, parenchymal } \\
\text { complications, or gastrointestinal tract } \\
\text { involvement) }\end{array}$ & \\
\hline
\end{tabular}

In present study, $51(92.7 \%)$ were male and $4(7.3 \%)$ were female.

The aetiology of acute pancreatitis was alcohol in 42 (76.33\%) cases; idiopathic in 11 (20\%) cases; trauma in 2 cases $(3.66 \%)$. Alcohol was the main aetiology in present study due to the high prevalence of alcohol consumption in the area where the present study was conducted .In study by Silverstein et $\mathrm{al}^{8}$, the most common aetiology of acute pancreatitis was alcohol (57 patients) followed by trauma (17 patients). In the present study, alcohol was the most common aetiology followed by idiopathic and trauma.

All patients in the present study had USG exam. Of them, 18 patients had poor visualisation of pancreas (32.72\%) while the other 37 patients had partial $(40.36 \%)$ or total $(26.9 \%)$ visualisation of the pancreas. The sensitivity of USG in detection of pancreatitis in present study was $41.8 \%(23 / 55)$ which was slightly higher than in the study by Silverstein et al $22.3 \%$, which could be due to the small number of subjects as well as the fact that almost all patients were lean and thin built.

\section{A Patient Came with H/o Abdominal Pain Since 15 days, B/l Pedal Oedema Since 4 days}

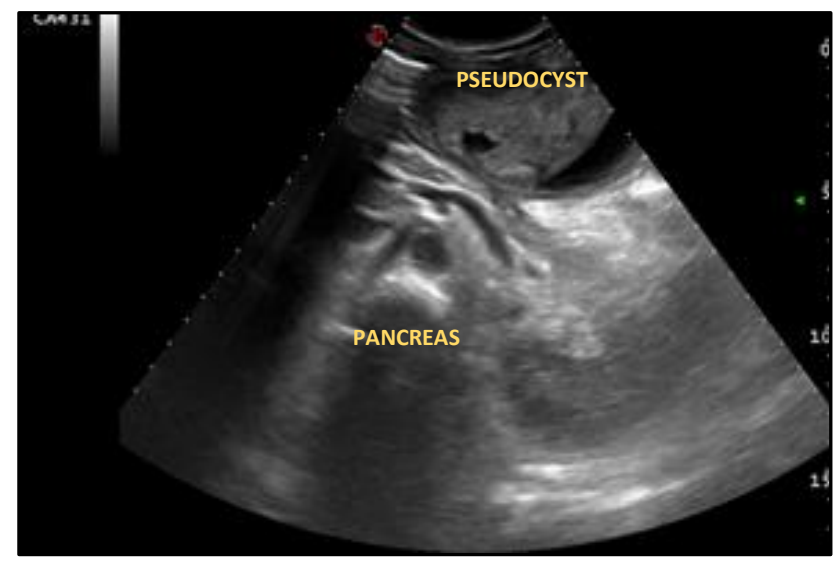

Fig. 1a

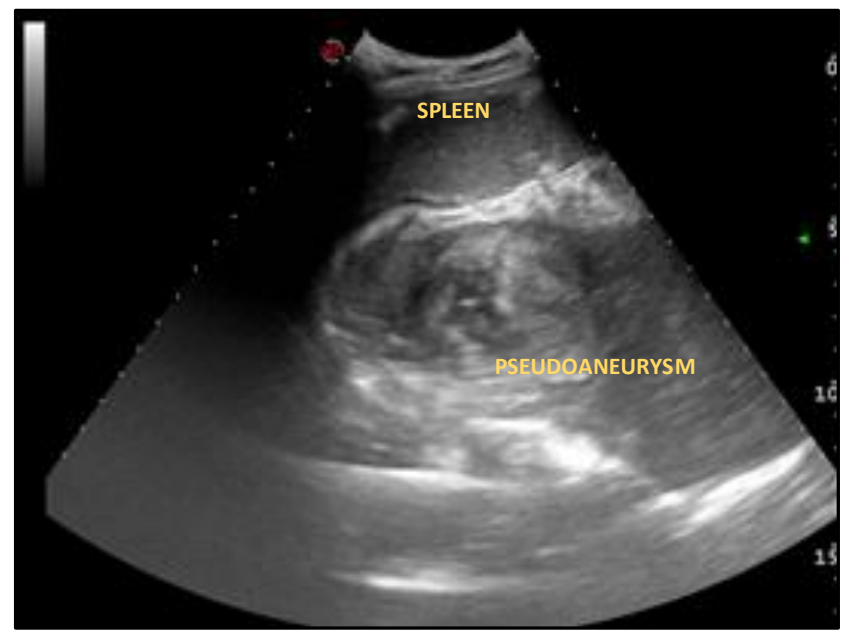

Fig. 1b 


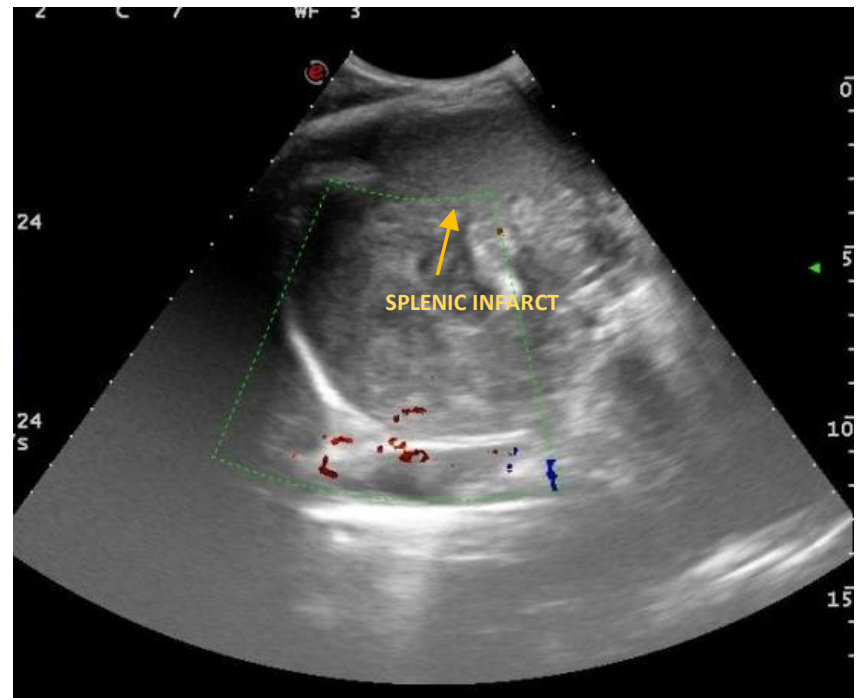

Fig. 2: USG abdomen shows a large heterogenous normal appearing collection posterior to stomach in the region of the tail of the pancreas. Pancreas not visualised clearly. Spleen shows multiple hypoechoic areas s/o Splenic infarcts

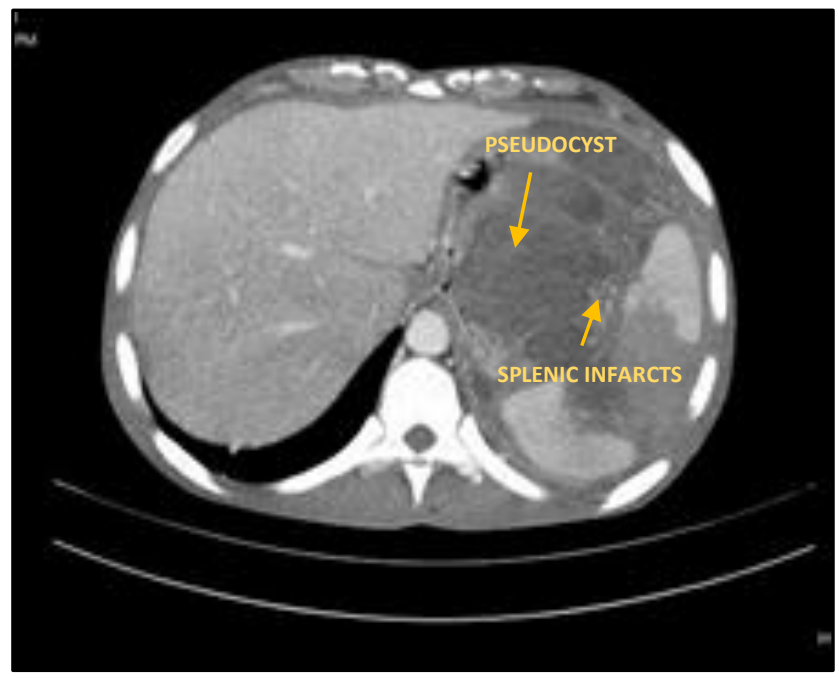

Fig. 3a

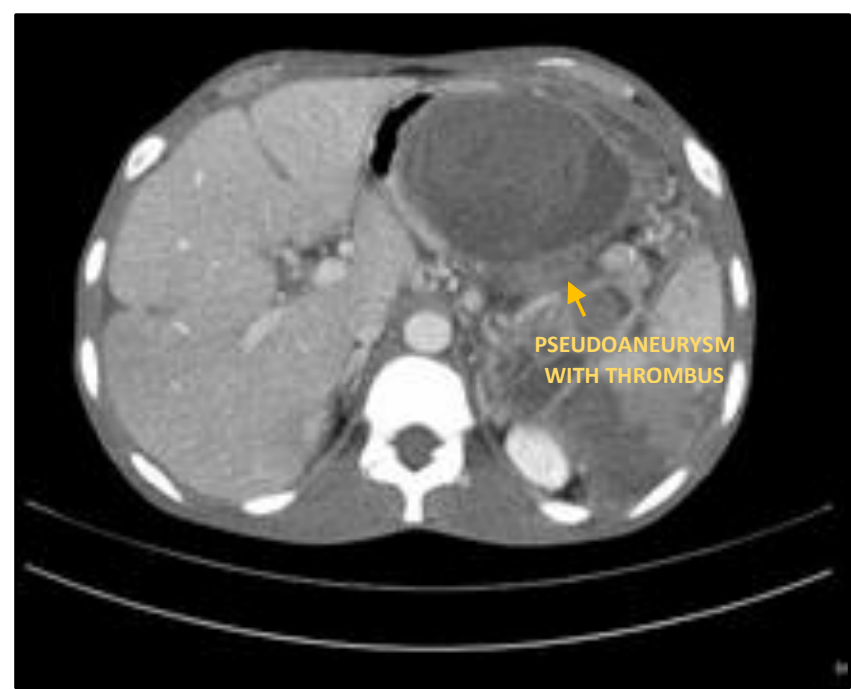

Fig. 3b

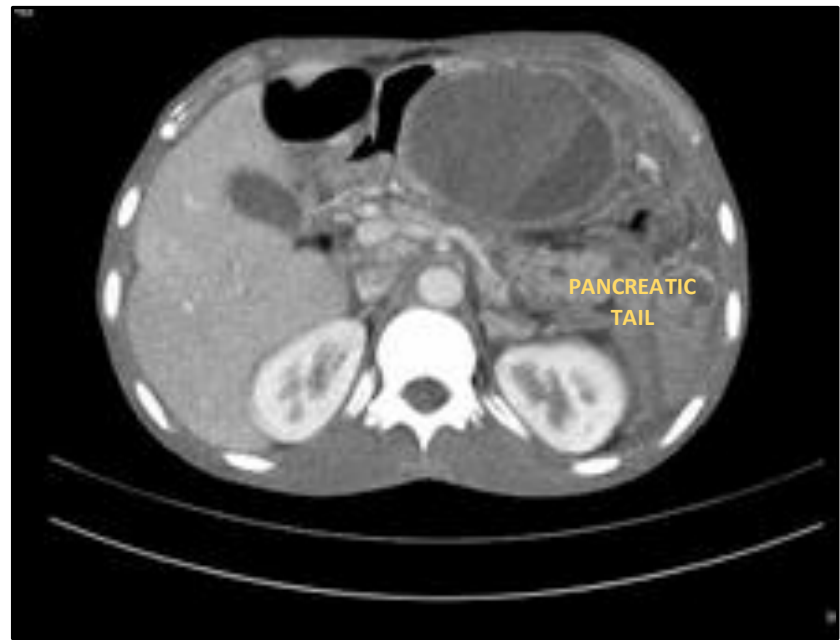

Fig. 3c

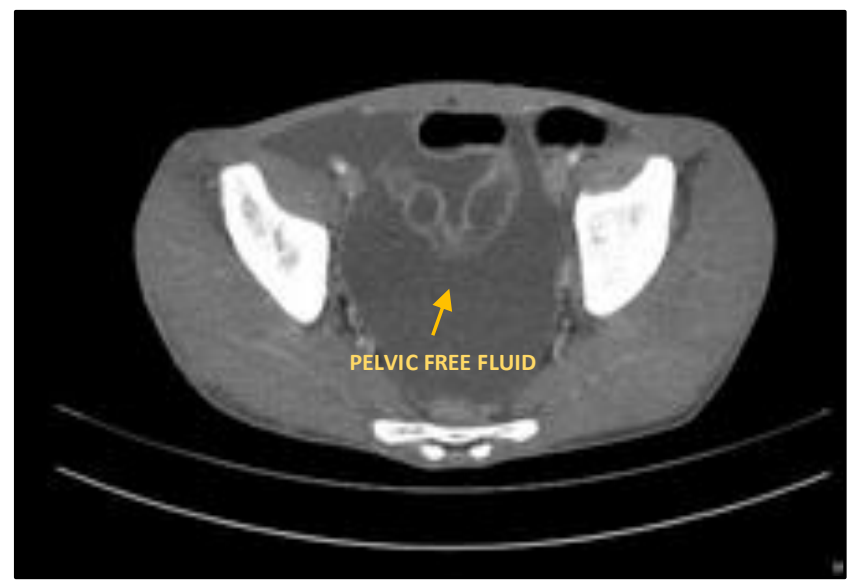

CECT abdomen shows heterogeneously enhancing pancreas with few hypodense areas at the tail of pancreas with peripheral enhancement and in continuation with the splenic vein s/o Pseudoaneurysm formation with thrombus in situ. Few peripheral pseudocysts are also seen with the above pseudoaneurysm eroding into the pseudocyst at the lesser sac. Spleen is increased in size with multiple irregular hypodense areas from upper to midpole s/o splenic infarcts. Moderate Free fluid noted in the pelvis

\section{DIAGNOSIS}

Acute pancreatitis with pseudocyst and pseudoaneurysm formation. MCTSI-10

In present study, CT findings co-related with the clinical type of acute pancreatitis. The overall sensitivity of CT in diagnosing acute pancreatitis was $100 \%$, which is almost similar to the study done by Michael C. Hill et al. ${ }^{9}$ The higher sensitivity of CT in the present study, in the detection of acute pancreatitis and acute on chronic pancreatitis may be because, most of the cases were of severe cases of pancreatitis with complications and also because of the smaller study group.

In the present study, contrast enhanced CT was $100 \%$ specific for detection of necrosis of pancreas. This finding is consistent with the findings proposed in the study of Owen J. O'Connor, Sebastian McWilliams et al.10

In the present study, the elevated serum lipase was found to have higher sensitivity $(89.09 \%)$ in detecting the acute 
pancreatitis than the serum amylase (65.4\%). This finding is similar to that of the study done by Treacy J et al. ${ }^{11}$ The higher sensitivity of both in the present study may be due to the fact that most of the cases were of severe pancreatitis and the small study group.

In the present study, there were five cases (19.04\%) which had vascular complications. Out of these, two cases had splenic vein thrombosis accounting to $5.4 \%$. This discrepancy in the present study with study by Bernades $P$ et al may be due to the small number of sample size in this study. ${ }^{12}$ In the present study of 55 cases, 37 cases $(67.27 \%)$ were detected as severe pancreatitis with MCTSI ranging from 8-10. This is in contrast to the study done by Nagar $\mathrm{AB}$ et al. ${ }^{13}$ The high incidence of severe pancreatitis may be due to the high volume of alcohol consumption in the area of study and also because of the low.socio-economic status of the sample population leading to the delay in hospital admission from the onset of symptoms, and thus leading to increased severity.

From the present study it can be evaluated that

\begin{tabular}{|c|c|}
\hline Ultrasound & Computed Tomography \\
\hline $\begin{array}{l}\text { Ultrasonography is } \\
\text { helpful in: } \\
\text { 1. Diagnosing pancreatitis. } \\
\text { 2. } \begin{array}{l}\text { Evaluating the } \\
\text { complications of } \\
\text { pancreatitis. }\end{array} \\
\text { 3. } \begin{array}{l}\text { Followup of diagnosed } \\
\text { cases. }\end{array} \\
\text { 4. } \begin{array}{l}\text { Detecting vascular } \\
\text { complications including } \\
\text { occlusion of the splenic } \\
\text { vein with secondary } \\
\text { development of varices } \\
\text { and pseudoaneurysms. } \\
\text { 5. Detecting pancreatic } \\
\text { ascites and pleural } \\
\text { effusion. }\end{array} \\
\text { Bedside evaluation of } \\
\text { pancreatitis. }\end{array}$ & $\begin{array}{l}\text { Advantages with CT } \\
\text { evaluation } \\
\text { 1. } \\
\text { High sensitivity and } \\
\text { specificity in } \\
\text { diagnosis of acute } \\
\text { pancreatitis } \\
\text { 2. } \\
\text { Better evaluation of } \\
\text { pancreatitis and } \\
\text { associated } \\
\text { complications with } \\
\text { better resolution } \\
\text { and multiplanar } \\
\text { visualisation with } \\
\text { MPR } \\
\text { reconstruction. } \\
\text { 3. Higher sensitivity } \\
\text { in evaluation of } \\
\text { pancreatic necrosis. } \\
\text { Good co-relation } \\
\text { between MCTSI } \\
\text { and duration of } \\
\text { hospital stay and } \\
\text { thus helps in } \\
\text { prognosis. } \\
\text { Helps in identifying } \\
\text { patients needing } \\
\text { surgical } \\
\text { intervention by } \\
\text { evaluation of } \\
\text { MCTSI }\end{array}$ \\
\hline 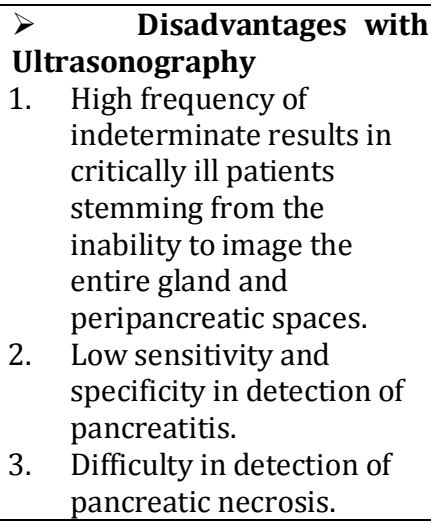 & $\begin{array}{l}\text { Disadvantages with } \\
\text { CT Evaluation- } \\
\text { 1. } \\
\text { Exposure to } \\
\text { radiation. } \\
\text { 2. Followup scan } \\
\\
\text { cannot be done } \\
\text { routinely. }\end{array}$ \\
\hline
\end{tabular}

\section{CONCLUSION}

The present study was performed to evaluate the role of CT in pancreatitis in which a total of 55 cases were studied and they were subjected to USG and CT (plain and contrast). It can be concluded that CT (plain and contrast) is superior in detecting and evaluating pancreatitis. USG is also a valuable initial investigation in detecting pancreatitis. However, the diagnosis may be missed due to poor visualisation by bowel gas. Ultrasound is the first line tool in the management and followup of complications of pancreatitis, in bedside imaging and for the interventions. Hence, CT (plain and contrast) should be performed in all cases of clinically suspected pancreatitis with positive serological findings.

\section{REFERENCES}

1. Frossard JL, Steer ML, Pastor CM. Acute pancreatitis. Lancet 2008;371(9607):143-52.

2. O'Connor OJ, Buckley JM, Maher MM. Imaging of the complications of acute pancreatitis. AJR 2011;197(3):W375-81.

3. Balthazar EJ. Contrast-enhanced computed tomography in severe acute pancreatitis. In: Bradley EL. edr. Acute pancreatitis: diagnosis and therapy. New York: Raven Press 1994:57-68.

4. Hill MC, Barkin J, Lsikoff MB, et al. Acute pancreatitis: clinical vs. CT findings. AJR 1982;139(2):263-9.

5. Balthazar EJ. Acute pancreatitis: assessment of severity with clinical and CT evaluation. Radiology 2002;223(3):603-13.

6. Ranson JH, Rifkind KM, Roses DF, et al. Objective early identification of severe acute pancreatitis. Am J Gastroenterol 1974;61(6):443-51.

7. Mortele KJ, Wiesner W, Intriere L, et al. A modified CT severity index for evaluating acute pancreatitis: improved correlation with patient outcome. Am J Roentgenol 2004;183(5):1261-5.

8. Silverstein W, Isikoff MB, Hill MC, et al. Diagnostic imaging of acute pancreatitis: prospective study using CT and sonography. AJR 1981;137(3):497-502.

9. Casas JD, Díaz R, Valderas G, et al. Prognostic value of CT in the early assessment of patients with acute pancreatitis. AJR 2004;182(3):569-74

10. O'Connor OJ, McWilliams S, Maher MM. Imaging of acute pancreatitis. AJR 2011;197(2):W221-W5.

11. Treacy J, Williams A, Bais R, et al. Evaluation of amylase and lipase in the diagnosis of acute pancreatitis. ANZ J Surg 2001;71(10):577-82.

12. Bernades $P$, Baetz A, Levy $P$, et al. Splenic and portal venous obstruction in chronic pancreatitis. A prospective longitudinal study of a medical-surgical series of 266 patients. Dig Dis Sci 1992;37(3):340-6.

13. Nagar AB, Gorelick FS. Epidemiology and pathophysiology of acute pancreatitis. In: Forsmark CE. edr. Pancreatitis and its complications. Totowa NJ: Humana 2005:3-15. 